\title{
Trinidadian Students' Knowledge Levels and Perceptions about Renewable Energy
}

\author{
Rawatee Maharaj-Sharma \\ The University of the West Indies, St. Augustine, Trinidad \& Tobago
}

\begin{abstract}
Many studies in science education have examined students' understandings and perceptions of key science concepts related to energy use, sources of energy and energy conservation practices. Only few have explored students' knowledge base and perceptions about renewable energy. The aim of this exploratory work is to survey the renewable energy knowledge base of secondary school science students in Trinidad and Tobago and to arrive at a position on what are their perceptions on the utility of renewable energy in a country which is heavily reliant on fossil fuels. To that end, a questionnaire consisting of dichotomous and Likert type questions as well as one open-ended question was administered to a group of 508 secondary school science students from both rural and urban areas in Trinidad and Tobago. The results indicate that students have the ability to distinguish between renewable and non-renewable sources, but have limited knowledge about the utility of renewable sources of energy. $76 \%$ of students are unaware of some sources such as biomass and $91 \%$ of them agree that solar panels should be considered for the country's supply of electricity. Most of the students in this work agree that renewable energy is a necessary energy option for the future. Generally, students' perceptions about transitioning to renewable energy were encouraging and supportive.
\end{abstract}

\section{Introduction}

At the global level, the focus on renewable energy in the context of environmental awareness is a major focus of curricula in many physical, biological and earth sciences programs as well as in all geography and environmental education programs. The United Nations World Commission on Environment and Development (WCED) (1987) advocates that targeting young persons and getting them to think critically about renewable energy is a priority [31]. At the Renewable Energy World Conference 2016 Conference held in Orlando, Florida (2016), it was suggested that renewable energy is here to stay and that the renewable energy transition is inevitable [25]. Acknowledging this inevitability therefore it is important that deliberate and decisive actions are taken to ensure that school curricula, particularly in the area of science, are designed and implemented with considerations of renewable energy in mind. Targeted education on renewable energy issues therefore should provide the requisite knowledge, understandings and appreciation which can help young people to prepare and to cope with present and future energy demands which have social, economic and environmental dimensions.

Renewable energy resources are sources used in the process of generating energy from - among other sources - wind power, sunlight and biomass. Renewable energy resources constitute an alternative to the traditional primary non-renewable energy carriers. Their resources are replenished in natural processes, which means they can be viewed as being practically inexhaustible. Moreover, generating energy from these sources is, in comparison to traditional (fossil) fuels, very environmentally friendly [5]. The potential of renewable energy resources has been known for a long time, but it is only over the last two decades that deliberate attempts have been made almost at an international level to put systems and infrastructure in place to harness much needed energy from these resources. The thrust is driven in large part by considerations of economics such as the exponentially rising demand for fuel, rising fuel costs, and the reality of depleting non-renewable resources. To an equal extent, the prompt to shift away from traditional energy sources to alternative sources is propelled by increased pressures placed on nation leaders to insist through sound policy initiatives that citizens adopt environmentally friendly behaviors and practices in their daily lives (Environmental Protection Agency, 2010), [7].

The shift away from non-renewable resources to renewable ones is viewed generally, as an unfamiliar undertaking and therefore, is not without its challenges. It requires a re-orientation in mindset and a transition in thinking which involves a constant awareness of preservation and conservation practices 
and personal interrogation of common regular habits [23]. In all societies, the school and by extension the education system is a good place to introduce information and ideas aimed at effecting long-term changes in beliefs, practices and habits [3]. In that regard, educational systems across the world have taken deliberate steps to include emphasis on environmental friendliness, renewable energies, energy conservation and environmental preservation in all physical, biological and earth science courses and programmes at all levels of the education system. This has been so in many jurisdictions for the better part of the last two decades (Education International, The Second World Congress of Education International Meeting, 1998) [6]. Trinidad and Tobago is no exception. All science and social studies curriculum documents in this twin island republic have explicit content linkages with relevant renewable energy considerations in the context of environmental issues. For example, one of the skills students are expected to develop in level 4 science in the topic conservation and sustainability is to be able to construct operational definitions of the terms renewable and non-renewable by interacting with visual and conceptual stimulus materials in a variety of activities. The expected learning outcome from these activities is that students should be able to classify energy sources as renewable or nonrenewable based on consideration of criteria such as supply, origin and replenishment. The expected disposition to accompany this skill is for students to recognize that the choice of renewable over nonrenewable can satisfy energy demands without compromising the quality of energy dependent tasks and experiences (Trinidad \& Tobago. Ministry of Education. Curriculum Guide, Science) [29].

Teachers, parents, policy makers and students in Trinidad and Tobago have now recognized the urgency of educational awareness in relation to conservation and sustainability and at this time have arrived at a comfortable transitioning point [22]. It therefore is an opportune time to examine fundamental knowledge-base, understandings and perceptions, which can serve to provoke this transition in Trinidad and Tobago and to assess the extent to which these may be positively influenced. The latter consideration, therefore, suggests that the most obvious place to start is in the classroom.

Trinidad and Tobago is known to be an industrialized nation with its abundance of oil and gas. The country is not known to have a renewable energy policy nor an environmentally friendly culture; though the latter is slowly changing at this time. Renewable energy considerations have only recently been given strong emphasis with the eminent closure of the country's state owned refinery and a massive restructuring exercise in the drilling and exploration sector of the industry. This restructuring will see the focus of the industry shifting from producing and refining to exploration and exportation with the energy needs of the country being met by importation. Though in its early stages, this change is expected to see higher energy costs for downstream industries, higher costs for electricity generation and ultimately for the citizens. With the inevitable depletion of nonrenewable resources, in spite of a semi-aggressive exploration thrust, the country is seriously looking at other sources of energy generators and have embarked on a diversification drive with the intention to harness energy from renewable energy sources to ensure the energy security of the nation. Trinidad and Tobago is located in tropics and by virtue of its tropical climate is well poised to aggressively pursue the possibilities of solar and to a lesser extent wind as viable energy sources. In addition, as a twin island republic the peripheral Caribbean Sea and Atlantic Ocean offers reasonable opportunity for serious consideration of hydroelectricity as an alternative source for generating electricity.

Trinidad and Tobago has the luxury of free education for all children at the Early Childhood, Primary and Secondary school levels. At each of these levels, students' education is guided by an official spiral curriculum [21]. Science is an integral component of the curricula in each of these levels and science curricula from the early childhood level to the upper secondary level have content related to sources of energy (including renewable and non-renewable), uses of energy, environmental awareness and preservation as well as issues about conservation of energy. As such, the existing composition of the science curriculum documents used to teach science in schools in Trinidad and Tobago make them enabling instruments through which teachers can easily infuse subject matter, scenarios and activities which can help students develop sound knowledge and understanding about renewable energy and also encourage them to think more carefully and critically about the role of renewable sources in the future.

Only few studies on students' views about sustainability and energy conservation practices exist in the Trinidad and Tobago context [20,22]. Even so these have not delved specifically into students' knowledge base of renewable energies or their perceptions of its use as an alternative to nonrenewable energy. This study is therefore the first to address in an explicit way, students' knowledge base and their perceptions about renewable energy in light of the inevitable shift away from non-renewable energy that will occur in the country. This study will provoke recognition and acceptance of renewable energy from a societal point of view and will highlight 
the role of education as a mediator that can serve to enhance students' pro-environmental perspectives to become informed and responsible future consumers. In that regard therefore, the following research questions have been tailored to guide the approach in this study:

1. What are the levels of knowledge of Trinidadian students about renewable energies?

2. How do Trinidadian students perceive renewable energy utilization at a time when the country is at a critical junction in terms of future energy sources?

In the conduct of this work, careful consideration of students' gender and their place of residence (urban or rural) will be noted and used to correlate the findings obtained. This work is significant, particularly in the Trinidad and Tobago context as it will provide new information for policy makers and planners to consider in the crafting of new national agendas about energy and energy resources as well as energy utilization for the future. It will also add to the international discourse on public awareness and willingness to adopt renewable energy in all long-term planning processes.

\section{Literature Review}

In Canada and the United States, while there is strong public awareness and support for wind energy as an alternative source to sustain the electricity grids, the public's understanding of the utility of wind power is poor, and basic knowledge about the potential of other renewable energy sources is sparse at most [14]. In fact, according to Klick and Smith (2010), 93\% of Canadians demonstrated awareness of wind energy and $96 \%$ supported further development of wind energy resources, but less than $10 \%$ had a functional understanding of what harnessing wind power for everyday usage entailed. This limited state of utility awareness is not unique to Canada or to the North American context, as Hsu (2008) and Tortop (2012) have also reported that there is an urgent need to raise levels of awareness in terms of energy consumption and the utility of renewable sources in the European and Asian contexts as well [10]. Lillemo (2014), has suggested that one way to raise awareness about the impact of excessive energy consumption arising from traditional energy sources is to couch renewable energy sensitization in the context of future environmental realities and in ways which target the end user of energy - the household consumers. This approach Lillemo (2014) reports, can lead to the emergence of a positive relationship between environmental awareness and engagement in everyday energy saving activities such as opening windows for daytime ventilation (in summer months) instead of using electric fans or air conditioning [16]. General public awareness and sensitization strong enough to prompt change in mindset and practices, is not easy to achieve when adult habits have been set by traditional ways of doing (Blazar and Kraft, 2017). Any attempt at effecting change must therefore target the young, those exposed to contemporary ways of thinking arising from exposure to formal as well as informal knowledge and experiences.

Since the UN conference on the Environment and Development in Rio de Janerio, held in 1992, a great emphasis has been placed on students' sensitization as future citizens of society, to acknowledge their responsibilities as the future energy consumers [30]. Education policy makers have been guided to encourage students and teachers to address issues of ecological sustainability and energy utilization as part of the fundamental education system of all participating nations, [30]. The school plays an important role for students' sensitization and the acquisition of sound knowledge about energy utilization and environmental sustainability. Students are generally, "open", less resistant to change and more eager to adapt to new practices and in that regard education has a leading role in molding perceptions and influencing informed behavior [1].

Studies involving secondary school students in Europe have indicated that the youth hold a generally positive attitude towards common renewable energy sources such as wind and solar, but revealed that their knowledge base and by extension the public understanding of the potential and possibilities of renewable energies is inadequate [28]. Students are more likely to embrace change which involves reducing the quantity of energy consumed and opting for consuming energy generated by renewable sources where these exist [17]. They are interested in promoting renewable sources of energy and supportive of conservative energy utilization practices. Young people, particularly those in formal school settings, are environmentally sensitive and have a good understanding of the link among renewable energies, energy conservation and environmental preservation; whether they are from fossil fuel deplete countries or countries with affluent supplies of fossil fuels $[1,13]$.

In Iran, a country like Trinidad and Tobago with a heavy reliance on fossil fuels despite its abundance of renewable energy sources, research has shown that there is an important need to educate students about the development of approaches and initiatives for a conscious transition to renewable energy sources [15]. According to this work, even though a majority of Iranian students has been exposed to the notion of renewable versus non-renewable energy sources, most 
are aware of solar and wind power as renewable sources but a relatively large percentage of students in Iran are unaware that biofuel is a renewable source. However, the majority of them have positive views about the utilization of renewable energy sources and share the view that a sustainable energy policy for the country is necessary.

In Trinidad and Tobago, a survey of young persons on matters related to sustainability and the environment revealed that young people are aware of environmental issues and energy utilization concerns but only a minority are driven to take environmentally defensive action [20]. Further work in Trinidad and Tobago showed that even while students in secondary school are exposed to subject matter about energy resources and energy utilization, they attribute no serious consideration to possibilities of transitioning to renewable sources seemingly because of the historic dependence on fossil fuels. This complacency is likely linked to the inconceivable inevitability that the nonrenewable sources which the country has grown accustomed to, will eventually be depleted [22]. In both works from Trinidad and Tobago, students from urban settings were more unconcerned about environmental preservation and energy conservation issues than rural students [20, 22].

\section{Methodology}

This exploratory study sought to ascertain the renewable energy knowledge base of a cross-section of secondary school science students in Trinidad and Tobago and to gauge their perceptions on the utilization of renewable sources of energy in the context of the country's heavy reliance on fossil fuels.

\subsection{Research Design}

This study proceeded via a mixed exploratory approach. An explorative approach was selected because the current work is concerned primarily with discovery and attempting to gain insights, with the researcher being the explorer [8]. The aim was to explore the research questions to arrive at a better understanding of the researched issues but not necessarily intending to offer final or conclusive solutions or answers. Stebbins (2001) describes this as social inquiry of the kind in which a determination on perspectives, positions, suppositions or even knowledge base is being solicited in order to arrive at comprehensive articulation of understandings or to allow for the emergence of "a state of mind" or "personal orientation" [26].

\subsection{Participants}

The students participating in this work were randomly selected from the second-year science class in 22 purposively selected schools across Trinidad and Tobago (11 urban schools and 11 rural schools). In the Trinidad and Tobago context, an urban school is defined as a school within a $12 \mathrm{~km}$ radius of any major city, borough or town; and a rural school is defined as a school that is located outside a $12 \mathrm{~km}$ radius from any major city, borough or town [19].

Class size ranged from 20 to 30 students for the schools and so to get a representative sample from each school the number of students selected from each school/class was two-thirds of the class size. To reduce the sampling bias in the selection of students, the hatand-draw method was used to select the students from each participating class to ensure that each student in each class had an equal chance of being selected to participate, and that each selection was purely by chance.

As a result of these selection procedures a group of 508 secondary school science students from 22 schools, all in their second year of secondary school science, participated in this work. The students were aged $12-14$ years and the group consisted of 293 girls and 215 boys. The group was a mixed one in terms of ethnicity, geographical origin, academic ability and social standing and consisted of 302 urban students and 206 rural students (rural class sizes are general smaller that urban class sizes in Trinidad and Tobago). Parental permission was subsequently sought for the students' participation and once this was obtained, the nature of the research and their role in the process were explained to the students. All students at this level in all secondary schools in Trinidad and Tobago are taught as prescribed by the Integrated Science syllabus which is the official curriculum document which guides secondary science education in Trinidad and Tobago [29]. Energy and energy related content are explicit in the integrated science syllabus with specific focus on forms, uses and sources of energy as well as energy transformations, conservation and preservation practices. Content related to sources of energy includes both renewable and non-renewable sources [29]. In addition to instructional objectives which advise teachers on what content is expected to be taught to students, the syllabus also contains suggested teaching and learning activities such as scenarios, case studies and topical debating.

\subsection{Instrumentation}

A questionnaire was developed for this study which comprised of two sections. Demographic data were sought in Section A while section B consisted of dichotomous statements, Likert scale type statements 
and an open-ended question which targeted the research questions of the study (Appendix I). For the dichotomous items students were presented with two response options (renewable or non-renewable) and were asked to select one to classify the nature of the sources of energy presented. These questions were aimed at eliciting students' knowledge on whether or not a given source of energy was renewable or nonrenewable. A total of 7 energy sources were provided to which students responded to indicate if they thought it was a renewable or a non-renewable source.

The Likert type questions were presented in two sections. Section I consisted of six questions on a 3point Likert scale with the range: agree, don't know and disagree $[2,12]$. The aim here was to ascertain students' knowledge level about the nature of renewable energy and their perceptions about the utility of renewable energy sources. Section II of the Likert questions also consisted of six questions but in this section the questions were presented on a 5-point Likert scale with the range: strongly disagree, disagree, uncertain, agree, strongly agree, [9]. These six Likert type items targeted students' knowledge and perceptions about specific practices and behaviors related to the utilization of energy resources now or in the future, in Trinidad and Tobago.

The open-ended question on the questionnaire was aimed at soliciting the general views of students about why they think it is necessary to transition to renewable sources of energy. It was phrased in a broad sense to allow students to respond freely. Students were asked to indicate if they thought it necessary to transition to renewable sources of energy (yes or no) and further to provide at least two reasons for their response.

\subsection{Instrument validation}

The draft questionnaire was sent to experts in the field of education, social sciences and renewable energy sciences. The draft instrument underwent three iterations based on feedback from meetings held on three separate occasions 2 weeks apart. Once there was consensus that the instrument was ready for testing, a semi-urban school in Trinidad was randomly selected and a group of second year secondary school science students in that school was asked to complete the questionnaire. This school was not a participating school in the study. A total of 32 questionnaires were distributed and 28 of them were returned. Students were encouraged to make notes in the space at the end of questionnaire to capture any difficulties they had completing it and if they felt there was anything that could be improved about the items on the questionnaire. In addition, 12 questionnaires were given to secondary school science teachers in 7 schools with a request to evaluate the appropriateness of the scientific content level the items on the questionnaire targeted. The validation exercise revealed that some items were ambiguously stated and needed rewording to clarify what was being asked. This was done and the finalized version of the questionnaire was prepared for distribution.

\subsection{Data Collection and Data Treatment}

In February 2017, before the onset of data collection, a formal letter was sent to the Ministry of Education in Trinidad and Tobago requesting permission to visit schools in the various educational districts for the purposes of administering the questionnaire. The Ministry of Education subsequently gave formal permission. Prior to administering the questionnaire, the researcher explained the questionnaire's aim and the items to the teacher with responsibility for each participating class. The researcher attended the questionnaire dissemination session in each school to provide clarification and assist students as required. Once the questionnaires were collected from all schools, SPSS 18.0 was used to generate descriptive statistics and frequencies in the analysis of the dichotomous responses and the Likert-type responses. Data obtained from the open-ended question were coded and analysed qualitatively as described by Creswell and Poth (2017), to reveal broad categories of students' views [4].

\section{Results}

\subsection{Familiarity with the nature of energy sources}

The first question in Section B of the questionnaire was the dichotomous question which sought to ascertain students' ability to distinguish between renewable and non-renewable sources of energy. Seven sources were provided, and students were invited to indicate which ones were renewable and which ones were non-renewable sources. Table 1 captures students' percentage responses to this question.

Table 1: Students ability to distinguish between renewable and non-renewable sources of energy (\% response)

\begin{tabular}{|l|l|l|l|}
\hline \multirow{2}{*}{$\begin{array}{l}\text { Energy } \\
\text { source }\end{array}$} & \multicolumn{3}{|l|}{ Response percentage $(\mathbf{N}=\mathbf{5 0 8})$} \\
\cline { 2 - 4 } & $\begin{array}{l}\text { Renewable } \\
(\%)\end{array}$ & $\begin{array}{l}\text { Non- } \\
\text { renewable } \\
(\%)\end{array}$ & $\begin{array}{l}\text { No } \\
\text { Response } \\
(\%)\end{array}$ \\
\hline Solar & 93 & 4 & 3 \\
\hline Wind & 93 & 2 & 5 \\
\hline
\end{tabular}




\begin{tabular}{|l|l|l|l|}
\hline Geothermal & 68 & 30 & 2 \\
\hline Fossil oil & 15 & 83 & 2 \\
\hline Coal & 13 & 85 & 2 \\
\hline Nuclear & 25 & 72 & 3 \\
\hline $\begin{array}{l}\text { Natural } \\
\text { Gas }\end{array}$ & 26 & 68 & 6 \\
\hline
\end{tabular}

Students had little difficulty classifying solar and wind as renewable sources of energy, but an interestingly large percentage of the students seemed to have difficulty determining the nature of geothermal energy. $30 \%$ of the students classified geothermal energy as a non-renewable source. While the reason for this misconception is not clear, an examination of the secondary school science curriculum documents in the sections which focus on energy sources, reveal that solar and wind are the more frequent examples of renewable energy sources discussed. Geothermal energy, as energy from within the earth, is mentioned but not discussed in detail in the curriculum documents.

In respect of the non-renewable sources, more than $65 \%$ of the students correctly identified all the examples provided as non-renewable. Natural gas was the example students were most uncertain about with $26 \%$ classifying natural gas as a renewable source of energy. Most students had no difficulty with fossil fuels and coal as $83 \%$ and $85 \%$ of the students respectively classified these as non-renewable sources. Approximately one-quarter of students surveyed classified natural gas as a renewable source, and while it is not certain what might have led to the misconception these students had, it is not unreasonable to assume that their misconception may be linked to prior knowledge and understandings about the nature of natural gas.

The demographic data allowed for an exploration of the extent to which school locality (urban or rural) and gender factored into students' classification of the 7 energy sources provided. It seems that locality had an evident effect on the correct classification of the sources provided but gender did not matter. Table 2 captures the percentage of students, by locality and gender, who accurately classified the sources provided as renewable or non-renewable.

Table 2 shows that in general, more students from urban settings were able to accurately classify the sources of energy presented. Among the 7 sources the largest percentages of accurate classification were obtained for solar and wind and these percentages were from urban students. In other words, while more urban than rural students knew the nature of all the sources, among the urban students, more of them knew the about the nature of solar and wind than the nature of coal, fossil fuels and natural gas. While there was no significant difference in the classification of wind as a renewable source in both localities, there was a significant difference in the classification of solar and geothermal, with the level of significance being greater in the case of the classification of geothermal. For the non-renewable sources there was, generally, no significant difference by locality, for all nonrenewable sources except fossil fuels, for which urban students showed better awareness of its classification as a non-renewable source.

For all sources (renewable and non-renewable) except fossil oil, coal and nuclear, gender difference was found to be not significant $(\mathrm{p}<0.05)$ even though it was clear that a larger percentage of females accurately classified these 3 as non-renewable sources. In other words, more female students seem to be aware of the nature of these three sources than their male colleagues.

Table 2: Students' classification of energy sources by locality and gender (\%)

\begin{tabular}{|c|c|c|c|c|c|c|}
\hline \multirow{3}{*}{$\begin{array}{l}\text { Energy } \\
\text { Source }\end{array}$} & \multicolumn{4}{|c|}{ Responses } & \multirow{2}{*}{\multicolumn{2}{|c|}{$\begin{array}{l}\text { Statistics } \\
\text { Chi-Square }\end{array}$}} \\
\hline & \multicolumn{2}{|c|}{$\begin{array}{l}\text { School } \\
\text { locality }\end{array}$} & \multicolumn{2}{|c|}{ Gender } & & \\
\hline & $\begin{array}{l}\text { Urb } \\
\text { an }\end{array}$ & $\begin{array}{l}\text { Rur } \\
\text { al }\end{array}$ & $\begin{array}{l}\text { Ma } \\
\text { le }\end{array}$ & $\begin{array}{l}\text { fem } \\
\text { ale }\end{array}$ & $\begin{array}{l}\text { Local } \\
\text { ity }\end{array}$ & $\begin{array}{l}\text { gend } \\
\text { er }\end{array}$ \\
\hline Solar & 98 & 96 & 97 & 98 & 0.003 & NS \\
\hline Wind & 96 & 94 & 93 & 96 & NS & NS \\
\hline $\begin{array}{l}\text { Geother } \\
\text { mal }\end{array}$ & 80 & 73 & 80 & 78 & 0.014 & NS \\
\hline $\begin{array}{l}\text { Fossil } \\
\text { fuels }\end{array}$ & 89 & 81 & 83 & 93 & 0.042 & $\begin{array}{l}0.00 \\
0\end{array}$ \\
\hline Coal & 83 & 80 & 77 & 87 & NS & $\begin{array}{l}0.00 \\
0\end{array}$ \\
\hline Nuclear & 78 & 78 & 71 & 82 & NS & $\begin{array}{l}0.00 \\
0\end{array}$ \\
\hline $\begin{array}{l}\text { Natural } \\
\text { gas }\end{array}$ & 66 & 67 & 63 & 67 & NS & NS \\
\hline
\end{tabular}

$P<0.05$ is considered significant

\subsection{Students' knowledge and utility awareness of renewable energy sources}

Students' awareness of the utility of renewable energy sources was further explored by analyzing their responses to six statements which described the nature and potential of most common renewable sources including hydro and biomass. Table 3 displays the findings of students' awareness. 
Table 3: Students' renewable energy knowledge and utility awareness $(\%)$

\begin{tabular}{|l|l|l|l|}
\hline Knowledge Item & Agree & Disagree & $\begin{array}{l}\text { Don't } \\
\text { Know }\end{array}$ \\
\hline $\begin{array}{l}\text { The sun's light can be } \\
\text { used to produce } \\
\text { electricity }\end{array}$ & 86 & 6 & 8 \\
\hline $\begin{array}{l}\text { Wind turbines can } \\
\text { harness wind energy } \\
\text { to produce electricity }\end{array}$ & 88 & 5 & 7 \\
\hline $\begin{array}{l}\text { Geothermal energy } \\
\text { comes from the } \\
\text { earth's internal } \\
\text { energy }\end{array}$ & 62 & 24 & 15 \\
\hline $\begin{array}{l}\text { Very large waterfalls } \\
\text { can be used to } \\
\text { generate } \\
\text { hydroelectricity }\end{array}$ & 60 & 12 & 28 \\
\hline $\begin{array}{l}\text { Bioenergy is the } \\
\text { energy produced } \\
\text { from plant biomass }\end{array}$ & 76 & 11 & 12 \\
\hline $\begin{array}{l}\text { Fermenting biomass } \\
\text { gives bioethanol }\end{array}$ & 28 & 10 & 52 \\
\hline
\end{tabular}

It was clear that many students were aware of the attributes of most renewable sources of energy and the potential of these sources as an alternative to nonrenewable sources. More than $85 \%$ of the students surveyed recognized that solar and wind sources can be harnessed to meet energy requirement needs. This finding may be linked to two factors - firstly students' native knowledge about the ease of accessibility of sunshine and wind due the geographical location of Trinidad and Tobago and secondly, to the heavy emphasis placed on solar and wind as alternative sources of energy in science curriculum documents. While geothermal and hydro sources are also discussed in science curriculum documents as examples of renewable sources of energy, these are not explored in detail and this may explain the relatively high percentage of students who were unaware (disagree or don't know), of the utility of these. About $40 \%$ of the students surveyed seemed unaware about the nature and origin of geothermal energy and a similar percentage of the respondents were unfamiliar with the notion of hydroelectricity.

Interestingly, a very high percentage of students seem to recognize the inherent possibility of biomass (76\%), but only about one-quarter of them (28\%) appeared to be aware of the process involved in the treatment of biomass in the production of energy. The explanation for this finding is unclear, but may be associated with the negligible emphasis placed on bioenergy in the science curriculum documents and hence on the teaching of this topic in science classrooms. Interestingly though, the process of fermentation is described in the curriculum documents in specific relation to yeast fermentation to yield alcohol products, but students did not seem to recognize that the process involved in treating biomass to yield bioethanol was conceptually similar.

\subsection{Students' knowledge and perceptions about energy related practices and behaviors}

Six statements about specific behaviors or practices related to energy usage which are aligned to the developing energy policies in Trinidad and Tobago, were presented to students and the extent of students' agreement or disagreement to the stated practices were evaluated using a 5-point Likert type scale. The statements targeted either currents practices students can adopt as well as futuristic renewable energy options suitable for the Trinidad and Tobago context. Table 4 summarizes students' perceptions in relation to current and futuristic energy utilization behaviors and practices.

Table 4: Students' perceptions in relation to current and futuristic energy utilization behaviors and practices

\begin{tabular}{|l|l|l|l|l|l|}
\hline $\begin{array}{l}\text { Energy SA } \\
\text { practice/behavior }\end{array}$ & A & U & D & SD \\
\hline $\begin{array}{l}\text { Dry laundry in outdoor } \\
\text { sunshine instead of the } \\
\text { dryer }\end{array}$ & 64 & 25 & 5 & 6 & 0 \\
\hline $\begin{array}{l}\text { Open windows for } \\
\text { ventilation instead of } \\
\text { using air-conditioning }\end{array}$ & 58 & 12 & 11 & 9 & 10 \\
\hline $\begin{array}{l}\text { Consider using solar } \\
\text { panels for household } \\
\text { electricity }\end{array}$ & 12 & 3 & 5 & 0 \\
\hline $\begin{array}{l}\text { Consider the option of } \\
\text { solar powered vehicles }\end{array}$ & 55 & 25 & 12 & 8 & 0 \\
\hline $\begin{array}{l}\text { Consider building a } \\
\text { nuclear plant }\end{array}$ & 21 & 20 & 45 & 4 & 10 \\
\hline $\begin{array}{l}\text { Engage in more reuse and } \\
\text { recycle to reduce energy } \\
\text { consumption }\end{array}$ & 82 & 14 & 1 & 3 & 0 \\
\hline
\end{tabular}

The geographical location of Trinidad and Tobago, its climate and its history of being heavily reliant on fossil fuels may all be linked to the findings captured in Table 4. The high percentage of students responding either agree or strongly agree to personally adopting practices which involve the preferred utilization of solar and wind sources, may suggest that students recognize the prevalence and ease of harnessing these sources in the Trinidad and Tobago context. It may also be that students have been sensitized to the practicality of these types of action through formal schooling where explicit reference is made in the guiding curriculum documents to examples of simple 
everyday changes which can be adopted to reduce the consumption of energy from non-renewable sources. For example, $89 \%$ of students agreed that utilization of the sun's energy to dry laundry was one way in which the consumption of non-renewable sources could be reduced while $70 \%$ of students agreed that reducing the use of electrical air-conditioning and instead opting for natural breeze was another practice they could adopt to reduce the use of energy generated from non-renewable sources. The idea of reuse and recycle is highly emphasized in formal schooling with the notable presence of recycle bins and composting pens in all 22 participating schools and this may explain the high percentage of students $(96 \%$ - agree and strongly agree) expressing agreement to engage in reuse and recycle practices. The concept of nuclear energy is one which students in Trinidad and Tobago are exposed to merely at the theoretical level as there are no nuclear plants or nuclear research facilities in the local (Trinidad and Tobago) or regional (Caribbean) contexts. This may explain the high percentage of students $(45 \%)$ who were uncertain about a nuclear plant in relation to futuristic energy considerations for the country.

\subsection{Students' views about transitioning to renewable energy}

Students' general views on transitioning to renewable sources of energy in the Trinidad and Tobago context were solicited through a single openended question. They were asked to indicate explicitly whether or not they agreed that is was necessary to make the transition and then to offer two reasons for their position. While the majority of responses were in favor of transitioning, there were students who did not support a move by Trinidad and Tobago to adopt renewable sources of energy. Some reasons were offered for the anti-transitioning position held by these students and these will be discussed.

For the majority of students in favor of Trinidad and Tobago making a bold transition to renewable sources of energy for future energy demands, thematic analysis of their written responses revealed the emergence of five themes from the collection of views expressed. Generally, students seem to recognize that non-renewable sources would not be available forever and that non-renewable sources are responsible in large part for many of the disturbing environmental issues that are confronting us at present. Many of them shared the view that Trinidad and Tobago has a global obligation to make this necessary transition. It is likely that learning outcomes from their schooling may have impacted on them in a very personal way to prompt the subjective expression of views they gave.
Iterative coding and categorizing consistent with the thematic analysis employed to treat with the data resulted in the following themes for students' views on transitioning to renewable sources of energy:

- Deplete-ability of non-renewable sources

- Environmental friendliness

- Sustainability

- Context availability

- Globally friendly

Deplete-ability. Most students expressed the view that for all generations to come there will continue to be the need for energy to survive and that non-renewable sources will eventually be unable to satisfy the continuous and gradually increasing energy demands. In recognition of this state of affairs, students indicated that there is urgent need to explore other [renewable] sources of energy to sustain future generations. The following extracts from students' responses attempt to capture the deplete-ability theme conveyed from their views:

“...non-renewable ones will finish one day and we will not have energy to live ... we must find other sources of energy to live ... and for people in the future to be able to live ..."

"Non-renewable sources will not be around forever ... we need to find others for when these are no longer around"

“... non-renewable sources are quickly finishing ...”

“... oil and coal will not be available always ... these things are used up ... they are not replenished ..."

Environmentally Friendly. Students were keen to recognize that the use of renewable sources of energy resulted in less air pollution and that they were actually 'cleaner' sources of energy. Many of their responses clearly expressed the understanding that making the transition to renewable energy sources was an environmentally friendly practice. This view is captured in the following extracts:

"Solar and wind energy do not produce pollution in the air ... like the fuels we use ... so the environment will be cleaner ..."

"renewable sources do not give off smog ... and smoke ..."

"... the air and the surroundings remain cleaner and fresher with these [renewable] types ..." 
Sustainability. The longevity of renewable sources of energy seem to be a concept student felt very strong about. Whether it was from their formal schooling or from informal experiences, at least one reason offered by almost all the students was linked to an understanding that renewable sources of energy were inexhaustible. The following is an exact excerpt from one student's response but which echoes the views expressed by almost all the students in this survey:

"Renewable energy will not finish so those who are living long after us will have enough energy to live and not have to worry that it [energy] will ever finish"

Context Availability. The majority of students who agreed that it was necessary for Trinidad and Tobago to transition to renewable sources of energy citied either the geographical location or the climatic characteristics or both, of Trinidad and Tobago as a strong reason for the transition. In fact, through their expressed views, it was clear that many students felt that the ease of availability of the resources, particularly solar and wind, is more than enough reason to prompt the country to invest in renewable energy. The following are examples of students' responses in support of the context availability theme:

“... in Trinidad and Tobago we have so much sun and so much wind all the time ... we should make use of it ..."

"we have sun all through the year ... it is easy for us to trap sunlight and use it for electricity ..."

“... being islands with plenty land and sea breeze we should build wind turbines to capture wind energy."

“... tropical climate means plentiful sun ... to use instead of fossil fuels"

Globally friendly. It seems that formal schooling in the area of energy use and energy conservation practices has sensitized students to changes that are taking place at the global level as many students cited the actions and changes that are happening at the international level in reference to the current energy crisis and the initiatives in renewable energies. Students were aware that the transition to renewable sources to satisfy current energy demands is in keeping with collective global trends and shared practices which many nations are signatories to. This theme is captured in the following extract:

\begin{abstract}
"The world is in an energy crisis ... everyone is looking to use renewable energy ... Trinidad and Tobago should do the same ..."
\end{abstract}

As indicated earlier, the majority of students gave favorable responses in support of transitioning to renewable sources, but a small minority provided responses which suggested a preference to continue with the heavy reliance on oil and gas Trinidad and Tobago is accustomed to. The theme which emerged from the minority views in this regard was labelled as "comfort zone" and the following is an excerpt which captures this theme:

$$
\begin{aligned}
& \text { “... yes, fossil fuels are getting lesser...but it } \\
& \text { will be many, many years before it's done ... } \\
& \text { this [fossil fuels] is working good for all the } \\
& \text { years ... why change now ... we don't know if } \\
& \text { these new [renewable sources] will work as } \\
& \text { good ...." }
\end{aligned}
$$

Overall students' views on transitioning to renewable sources are summarized in Table 5.

Table 5: Student \% for Emerging Themes

\begin{tabular}{|l|l|}
\hline Theme & \% of students \\
\hline Deplete-ability & 72 \\
\hline Environmental friendliness & 40 \\
\hline Sustainability & 48 \\
\hline Context availability & 60 \\
\hline Globally friendly & 36 \\
\hline Comfort zone & 3 \\
\hline
\end{tabular}

\section{Discussion}

The main objectives of this work were to explore the renewable energy knowledge base of secondary school science students in Trinidad and Tobago and to arrive at a position on what are their perceptions on the consumption and utility of renewable energy. The exploration has revealed that secondary school science students are generally well aware of the distinction between renewable and non-renewable energy sources and that urban students and urban girls in particular are most knowledgeable about the distinction. Geothermal and hydro sources of renewable energy were most unfamiliar to students of both genders and from both urban and rural localities. This finding is in some ways similar to those reported by MacKay (2009), but the extent of unfamiliarity with geothermal and hydro was lesser in the current work [18]. Israel, Wong-Parodi, Webler and Stern (2012) solicited students' knowledge base about shale oil as well, and found that it was comparable with that of geothermal and hydro. 
Knowledge base on shale oil however, was not explored in this work [11].

While this work revealed that urban students were more knowledgeable about the nature and utility of renewable energy sources, cultural dispositions in Trinidad and Tobago suggest the contrary. In other words, persons who live in rural communities are culturally, lower energy consumers and are more energy conservative [22]. The exact reason for this deviation from earlier findings is uncertain and may not necessarily be linked to their habits and practices, but may be as a consequence of increased awareness resulting from higher levels of exposure to information from sources outside formal schooling, such as television, newspapers and social media. Rural communities in Trinidad and Tobago, are not as exposed to these informal sources of information as urban communities. Further exploration of this relationship between informal exposure to knowledge and perceived awareness, as well as actual energy consumption practices can form the basis of an interesting study emerging from this work.

In terms of the utility awareness of renewable energy sources, more than $50 \%$ of the students demonstrated awareness of the fact that renewable sources can practically replace non-renewable sources to meet current energy needs. They cited the role of harnessing energy from renewable sources but were not familiar with details of the harnessing processes particularly in the case of geothermal and biomass sources. A similar finding was reported by Klick and Smith (2010). While knowledge about harnessing procedures were not explored in this work, the high percentage of students who agreed that solar and wind sources can be used to supply electricity needs, suggest that students may have some ideas about the possible ways in which these two sources could be harnessed. Formal schooling does in fact focus heavily on solar and wind sources and may explain the higher levels of confidence students seem to have about discussing these. Eliciting, in detail, students' knowledge base about the harnessing processes can be explored in subsequent work.

Students' current and futuristic practices were in alignment with their utility awareness of renewable sources of energy. The majority of students recognized that many common everyday practices and habits can be easily transformed into more energy friendly behaviours. It seemed to be that students were aware of lifestyle changes that can be made e.g. more reuse and recycle, but may not have been exposed to the provocation to compel them to make these changes. Empirical research done by Stevenson (2007) and Maharaj-Sharma (2015), suggest that unless human behavior in respect of environmental preservation is challenged either by confrontation with a dreaded reality or by a direct and present consequence, persons are unlikely to act in positive environmentally friendly ways and with urgency. The findings in this work seem to support this notion [22, 27].

For most of the students in this work, views about transitioning to renewable energy were very favorable and this level of favorability was linked in large part to the recognition that non-renewable sources are deplete-able and also to the appreciation of the abundance of sunshine and wind that is available in the island setting of Trinidad and Tobago. An average of $41 \%$ of the students favored the transitioning to renewable sources for reasons linked to either sustainability or environmental/global friendliness. A similar finding was reported by Owens and Driffill (2008) in respect of sustainability and environmental considerations when students' views on shifting to more renewable sources were explored [24].

Overall this work shows that at the most influential level, the school level, students are aware of the energy crisis the world is experiencing and further that they recognize the continued negative impact human behavior and practices are having on the crisis. Their knowledge level about renewable energies is relatively high. They understand that more must be done at the individual level to conserve energy and to preserve the environment. Trinidadian secondary school science students recognize that the country is at a critical juncture in its development. It is a time when the country's reliance on fossil fossils is threatened and therefore non-renewable sources of energy must be expediently explored. They realize that anything less will have serious implications for the availability of energy in the future. They lament however that they feel powerless when it comes to influencing policy decisions at the country level, but they are firm in their view that policy incentives to promote capacity building in the technology to harness, channel and promote utilization of renewable energy on a large scale is needed in Trinidad and Tobago. Transitioning to renewable sources of energy is an inevitable necessity. The latter view, from students, having been revealed from this work, suggest that there is need to encourage and engage those in the country who have influential capacities and resources to become active partners in the transitioning efforts. One possibility might be for the state to explore the establishment of incentive-based investment in renewable energy initiatives which would provide attractive stimulus for private sector engagement in the facilitation and realization of the long-term transitioning goal. 


\section{References}

[1] Abraham, M., \& Arjunan, N. K. (2005). Environmental interest of secondary school students in relation to their environmental attitude. Perspective in Education, 21(2), 100-110.

[2] Allen, I.E. \& Seaman, C.A. (2007). Likert scales and data analyses, Quality Progress, 40(7), 64-65.

[3] Blazar, D., \& Kraft, M.A. (2017). Teacher and teaching effects on students' attitudes and behaviours, Educational Evaluation and Policy Analysis, 39(1), 146-170.

[4] Creswell, J.W., \& Poth, C.N. (2017). Qualitative inquiry and research design: Choosing among five approaches. London, UK: Sage.

[5] Deyette, J., \& Freese, B. (2010). Burning coal, burning cash: Ranking the states that import the most coal. Cambridge, MA: Union of Concerned Scientists.

[6] Education International, 2nd World Congress of Education International Meeting, Washington DC, 2529 July, 1998.

[7] Environmental Protection Agency. 2010. Assessing the Multiple Benefits of Clean Energy: A Resource for States. Chapter 5.

[8] Gravetter, F.J., \& Forzano, L.B. (2011). Research Methods for the Behavioural Sciences, Belmont, CA: Wadsworth Cengage Learning.

[9] Halder, P., Pietarinen, J., Havu-Nuutinen, S., \& Pelkonon, P. (2010). Young citizens' knowledge and perceptions of bioenergy and future policy implications, Energy policy 38 (6), 3058-3066.

[10] Hsu, S-J. (2010). The effects of an environmental education program on responsible environmental behavior and associated environmental literacy variables in Taiwanese college students. Journal of Environmental Education, 35(2), 37-48. doi:10.3200/JOEE.35.2.37-48.

[11] Israel, A.L., Wong-Parodi, G., Webler, T., \& Stern, P.C. (2012). Eliciting public concerns about an emerging energy technology: The case of unconventional shale gas development in the United States. Energy Research \& Social Science, 8:139-150.
[12] Jacob, J., \& Matell, M.S. (1971) Three-Point Likert Scales Are Good Enough, Journal of Marketing Research, 8(4), 495-500.

[13] Khan, S. H. (2013). A study of attitude towards environmental awareness in relation to certain variables among senior secondary students. Global Research Analysis, 2(4): 42-44.

[14] Klick, H., \& Smith, E. (2010). Public understanding of and support for wind power in the United States. Renewable Energy 35, 1585-1591.

[15] Komendantova N, Yazdanpanah M, \& Shafiei R (2018). Studying young people' views on deployment of renewable energy sources in Iran through the lenses of social cognitive theory. AIMS Energy, 6 (2): 216228.

[16] Lillemo, S.C. (2014). Measuring the effect of procrastination and environmental awareness on households' energy-saving behaviours: An empirical approach. Energy Policy, 66, 249-256.

[17] Lee, E. B. (2008). Environmental attitudes and information sources among African American college students. Journal of Environmental Education, 40(1), 29-42. doi:10.3200/JOEE.40.1.29-42.

[18] MacKay, D. (2009). Sustainable Energy Without the Hot Air. Cambridge, UK: UIT Cambridge Ltd.

[19] Maharaj-Sharma, R. (2007). Students' attitudes to science in urban and rural schools in Trinidad and Tobago. Caribbean Curriculum, 14, 31-47.

[20] Maharaj-Sharma, R. (2010). Young people's views on the importance of conserving the environment. Caribbean Curriculum, 17, 1-15.

[21] Maharaj-Sharma, R. \& Sharma, A. (2014). A case study of what experiences contribute to the ides of energy held by primary school students in Trinidad and Tobago. European J of Physics Education, 5(4), 112 .

[22] Maharaj-Sharma, R. (2015). Awareness of and responsiveness to environmental issues: Views from secondary school students in Trinidad and Tobago. Caribbean Curriculum, 23, 79-97.

[23] Martin, J.L., Maris, V. \& Simberloff, D.S. (2016). The need to respect nature and its limits challenges society and conservation science. Proceedings of the 
National Academy of Sciences of the United States of America, 113(22), 6105-6112.

[24] Owens S., \& Driffill L. (2008). How to change attitudes and behaviours in the context of energy. Energy Policy. 36: 4412-4418.

[25] Renewable Energy World Conference \& Expo North America, Orlando, FL, 13-15 December, 2016. [26] Stebbins, R. A. (2001). Exploratory research in the social sciences. London, UK: Sage.

[27] Stevenson, R.B. (2007). Schooling and environment education: Contradictions in purpose and practice. Environmental Education Research, 13(2), 139-153. Doi: 10.1080/13504620701295726.

[28] Tortop, H.S. (2012). Awareness and misconceptions of high school students about renewable energy resources and applications: Turkey case. Energy Education Science and Technology Part B: Social and Educational Studies, 4(3), 1829-1840.

[29] Trinidad and Tobago. Ministry of Education. (2010). eConnect and Learn programme policy Version 4; draft. Port of Spain, Trinidad: Author.

[30] United Nations Conference on Environment and Development, UNCED, Rio de Janeiro, 3-14 June, 1992.

[31] World Commission on Environment and Development. (1987). Our common future. Retrieved from http://www.un-documents.net/wced-ocf.html. 


\section{Appendix 1 - Questionnaire}

Please read the instructions provided in each section of this survey and respond as truthfully as you can.

\section{Section A - Circle the option which applies to you.}

Gender: Male Female

School type: Urban

Rural

\section{Section B (Dichotomous Questions)}

Seven (7) energy sources are provided in the table below. Please indicate which ones are renewable sources and which ones are non-renewable sources by ticking the appropriate box.

\begin{tabular}{|l|l|l|}
\hline Energy Source & Renewable & Non-Renewable \\
\hline Solar & & \\
\hline Wind & & \\
\hline Geothermal & & \\
\hline Fossil & & \\
\hline Coal & & \\
\hline Nuclear & & \\
\hline Natural gas & & \\
\hline
\end{tabular}

\section{Section B (Likert Type statements) - I}

Read the six statements in the left-hand column and indicate whether you agree, disagree or don't know by ticking the appropriate box.

\begin{tabular}{|l|l|l|l|}
\hline Statement & Agree & Disagree & Don't Know \\
\hline The sun's light can be used to produce electricity & & & \\
\hline Wind turbines can harness wind energy to produce electricity & & & \\
\hline Geothermal energy arises from the earth's internal energy & & & \\
\hline Very high waterfalls can be used to generate hydroelectricity & & & \\
\hline Bioenergy is the energy produced from plant biomass & & & \\
\hline Fermenting biomass gives bioethanol & & & \\
\hline
\end{tabular}

\section{Section B (Likert Type statements) - II}

Examine carefully the 6 energy practices/behaviors presented in the left-hand column and indicate the extent of your agreement (or disagreement) to each one by ticking the appropriate box.

\begin{tabular}{|c|c|c|c|c|c|}
\hline Statement & SA & A & $\mathrm{U}$ & $\mathrm{D}$ & SD \\
\hline Dry laundry in outdoor sunshine instead of the dryer & & & & & \\
\hline Open windows for ventilation instead of using air-conditioning & & & & & \\
\hline Consider using solar panels for household electricity & & & & & \\
\hline Consider the option of solar powered vehicles & & & & & \\
\hline Consider building a nuclear plant & & & & & \\
\hline Engage in more reuse and recycle to reduce energy consumption & & & & & \\
\hline
\end{tabular}

\section{Open-ended Question}

Respond to the following question as freely as you wish:

Considering your knowledge and understanding of the global energy crisis currently facing the world, do you think it is necessary for Trinidad and Tobago to move away from using non-renewable sources of energy to using renewable sources (yes or no)? Give two reasons for your response. 